\title{
Who benefits from hospital birth? Perceptions of medicalised pregnancy and childbirth among Andean migrants in Santa Cruz de la Sierra, Bolivia
}

\author{
KAROLINA KUBERSKA, PhD, University of Birmingham ${ }^{a}$ \\ k.kuberska@bham.ac.uk
}

\begin{abstract}
This paper uses ethnographic data on reproductive experiences of indigenous Andean migrant women in the lowland eastern Bolivian city of Santa Cruz de la Sierra as a starting point for discussion of different perspectives on the efforts of the Bolivian state to biomedicalise the processes of pregnancy and childbirth. Pregnant women and babies up to six months of age are covered by the state-funded Universal Mother-Infant Insurance (SUMI) that favours the use of biomedical facilities over the services of traditional midwives that are not covered by the insurance. Unlike in the western Andean highlands of Bolivia, most women in Santa Cruz give birth in hospitals while actively negotiating their options. They are not motivated by strictly medical factors as social or economic circumstances also come into play. Simultaneously, the increased levels of hospital deliveries in Bolivia translate into decreased levels of maternal and perinatal mortality, which in turn help Bolivian statistics to fare better from the point of view of the government and international bodies, such as the WHO. However, the restrictions on qualifying for SUMI are such that women in Santa Cruz are often forced to meet the costs of medical services themselves. I argue that the initial socio-biomedical intention of SUMI has become obscured by its political impact.
\end{abstract}

Keywords: biomedicalization; traditional medicine; migration; childbirth; Santa Cruz de la Sierra; indigenous peoples.

\footnotetext{
${ }^{a}$ I am a medical anthropologist with background in cognitive linguistics. The core of my research interests lies within the scope of medical anthropology, with a specific focus on maternal health. My previous research project looked at postnatal health of Andean migrant women in a lowland Bolivian city of Santa Cruz de la Sierra. More particularly, I studied the ways in which a typically Andean postpartum illness occurring in an unusual lowland setting could be seen as a social problem, rather than just a bodily dysfunction. I focused on the relationships between emotions, sociality, and well-being as well as understandings of the body that incorporate traditional and biomedical notions.
}

In September 2016 I joined the University of Birmingham as a postdoctoral fellow on an Economic and Social Research Council-funded project "Death Before Birth: Understanding, informing and supporting the choices made by people who have experienced miscarriage, termination, and stillbirth" that explores socio-legal intersections of decision-making processes in the experiences of pregnancy loss. I am particularly interested in the understandings of personhood, kinship, memory-making as well as bereavement care pathways. 


\section{Introduction}

The goal of this paper is to highlight the complex ways in which pregnancy and childbirth are perceived and experienced by Andean migrants in Santa Cruz de la Sierra, Bolivia. What makes this ethnographic context particularly interesting is the degree to which biomedicalization of female health is privileged by the state authorities by means of national health care policies that specifically target pregnant women as well as their babies and young children. Despite the magnitude and far-reaching consequences of government decisions to introduce maternal health insurance, there are numerous other factors at play, including the decrease in the number of local midwives, views promoted in the media through information campaigns, availability of private health care at reasonably low prices, as well as difficult financial situations that so many women (and men) in Bolivia face every day. These aspects will be discussed in order to highlight their inextricable entanglement that continually transforms the perceptions of pregnancy and childbirth. However, migrant women in Santa Cruz are not unresisting in this process; they make decisions about their reproductive choices in an active manner, combining knowledge about pregnancy from Andean medical traditions with what they are learning from sources favouring the biomedical perspective.

The case of Bolivia is particularly interesting in that there exists a considerable difference between the eastern lowland and western highland parts of the country, despite identical legislation and the availability of a national health insurance programme. Bolivian highlands are more densely populated by more ethnically homogenous people, a large portion of whom are Quechua and Aymara-speaking indigenous groups with their rich medical traditions that successfully compete with biomedicine in a medically plural landscape in western Bolivia (Loza, 2008). Santa Cruz de la Sierra, on the other hand, historically constructing itself as a modern, outward-looking city (Manzoni, 2005), privileged biomedicine as one of modernity's hallmarks. In the context of pregnancy and childbirth in the city of Santa 
Cruz de la Sierra, the almost complete absence of midwives, traditional and biomedical, limited the practical horizon of childbearing to biomedical institutions. I would argue, however, that this has not had a homogenising effect on the perceptions of pregnancy and childbirth as might be assumed. In fact, Andean migrant women in Santa Cruz I worked with recognised the choices available to them in pregnancy in a manner that was nuanced and sophisticated, despite the fact that most of their available options would need to be accessed within a biomedical context.

In general, it can be said that, when it comes to pregnancy, women's local knowledge has been overshadowed by biomedicine, access to which is strongly encouraged by the state (see e.g. Loza, 2013, p. 1084). ${ }^{1}$ Hospital births are promoted in media campaigns and through a national health service aimed specifically at pregnant women and their babies, the Seguro Universal Materno-Infantil, or SUMI (Universal Mother-Infant Insurance), as well as via statedispensed, means-tested small cash stipends known as the Bono Juana Azurduy (Juana Azurduy Stipend. At present, SUMI guarantees free medical care in state-run hospitals to all women who are pregnant or have given birth in the preceding six months as well as to children up to five years of age (Ministerio de Salud y Deportes, 2006). Moreover, women who receive antenatal checks at regular intervals, give birth in one of the designated hospitals, as well as attend postnatal appointments for themselves and their babies qualify for the Bono Juana Azurduy, a financial incentive especially attractive to the economically disadvantaged.

The case of reproductive choices for Andean migrant women in Santa Cruz illustrates how health matters are deeply embedded not just in the medical, but also the social, cultural, economic, and political spheres of people's lives. The virtual inexistence of midwives in the

\footnotetext{
${ }^{1}$ In a fascinating study of the coexistence of biomedical healthcare and Andean medicine in two rural communities in Peru and Bolivia, researchers concluded that "the health-seeking strategies of households in Waca Playa [Department of Cochabamba, Bolivia] and Pitumarca [Department of Cuzco, Peru] are basically independent of the level of access to biomedicine, except for some specific practices such as childbirth", that almost invariably take place within a biomedical context (Mathez-Stiefel, Vandebroek \& Rist, 2012, p. 10, my emphasis).
} 
city of Santa Cruz means that most women, including migrant women, give birth in biomedical facilities, but the way they choose the place for delivery - and, more importantly, how they explain and interpret the choices they make - is influenced by a variety of factors, some of which have very little to do with the effectiveness of biomedicine in lowering maternal and child mortality. Simultaneously, the fact that most women in Santa Cruz give birth in hospitals produces statistical results which demonstrate Bolivia's "progress" as a developing country in the eyes of Bolivian government and the world. These co-existing perspectives do not readily translate into each other, maintaining a powerful tension between the local and global priorities.

\section{Methodology}

I spent approximately fourteen months living in the suburbs of the city of Santa Cruz de la Sierra in eastern Bolivia, carrying out research on the topic of sobreparto, a traditional Andean postpartum illness. ${ }^{2}$ Sobreparto is understood to be caused by exposing the body to excessive heat or cold during the postpartum period, for instance, by doing the laundry by hand, sweeping the floor or cooking. Symptoms involve general weakness, fever, cold sweats, all of which make it difficult for the woman to take care of her baby. This condition is believed to fall beyond the scope of biomedicine; women I worked with often said: “doctors don't know how to cure it." The healing process involves massaging the body with fat as well as drinking herbal infusions, usually containing rosemary. The aetiology of sobreparto as explained by Andean migrant women in Santa Cruz falls within the traditional Andean understandings of the body and health (see e.g. Larme \& Leatherman, 2003). In my study I sought to position this condition in a wider spatio-temporal frame, one that would include - or even extend beyond the entire pregnancy. By extending the scope of my research interests, I was able to gain insight not only into the illness, which was the original topic of my research, but also into more subtle

\footnotetext{
${ }^{2}$ See Kuberska (2016). There are numerous ethnographies describing the phenomenon of sobreparto in the Andes - especially in highland areas of Peru and Bolivia; the most recent works include: Loza and Álvarez (2011), Luerssen (2011), Leatherman (2005), Finermann (2004), Larme and Leatherman (2003), Bradby and MurphyLawless (2002), Leatherman (1998), or Larme (1993).
} 
changes about women's attitudes towards their consecutive pregnancies. I collected a number of in-depth narratives of reproductive trajectories of Andean migrant women to the city of Santa Cruz. Women that I worked with were approached using my personal contacts from 2009, when I previously carried out research in Santa Cruz, as well as snowball sampling ${ }^{3}$ - where my informants and friends suggested other people who might want to speak to me about their experiences of sobreparto. It was important for me to build a relationship with these women, as a result I held multiple conversations with each of them on the topic of reproduction throughout my fieldwork, during which I took notes. This allowed me to gather much detail on each life story, establish clear chronology of events, and ask follow-up questions on multiple occasions. Towards the end of my fieldwork, I audio-recorded one or two semi-structured interviews with each woman. I also interviewed traditional medical practitioners, including midwives as well as representatives of local biomedical health authorities. In this paper, I specifically draw on the descriptions of pregnancies and labour that combined traditional and biomedical concepts.

Narratives about pregnancies were as varied as their authors, but most combined biomedical and common-knowledge categories. This was to be expected in the context of Santa Cruz, where the majority of women give birth in biomedical facilities. Generally speaking, biomedical categories involved technical names for body parts, such as "el cordon umbílico" (umbilical cord), rather than "el cordón" (cord), or names of medical conditions, such as preeclampsia. Common knowledge categories manifested through special attributes ascribed to the fetus, e.g. one of my informants insisted that every time she was pregnant with the boy, she knew it early in the pregnancy since "the baby was kicking from the second month". In the Andes, it is commonly believed that male fetuses are more active and become formed earlier in the womb, as opposed to female fetuses, who are passive and their full formation occurs in the

\footnotetext{
${ }^{3}$ Snowball sampling has multiple advantages when recruiting participants with characteristics that are not visible - in the case of my research, the experience of sobreparto (see e.g. Bernard, 2011).
} 
later stages of pregnancy (Morgan, 1997). Another woman I interviewed called her C-section scar with a dramatic-sounding phrase "mi herida", my wound, and claimed that it had not fully healed even though her baby was over 12 months old. She continued to wear elastic underwear to keep it tight, as she explained, to help her uterus from remaining permanently enlarged. Wearing such shapewear in Santa Cruz constitutes a modern equivalent of faja (girdle), which in the past was typically fashioned out of a square piece of fabric, folded into a triangle, used to tie the abdomen after childbirth. It is possible that discourse in the accounts of past gestations could have been influenced by biomedical knowledge acquired after the pregnancy. What remains significant, however, is the fact that women meaningfully combine different domains of knowledge when discussing matters of reproduction.

\section{Reproduction, society, and the Bolivian state health strategies}

Even without extensive research into the topic, most people have an intuitive understanding of what the idea of pregnancy in Euro-American society entails. The conceptualisation of pregnancy transformed from it being a woman's concern, to prioritising the authority and expertise of (initially exclusively male) biomedical doctors, to women (re)gaining their say - at least to a certain extent - about what happens with and to their bodies during pregnancy and childbirth. One of the greatest shifts, however, involved positioning pregnancy on the health and illness axis (see e.g. Martin, 2001), and consistently pushing it towards the latter. Despite the fact that no sane person would explicitly call pregnancy an "illness", it is doubtful that many Euro-American expectant mothers who would refuse antenatal check-ups on this principle alone.

The phenomena of pregnancy and childbirth in Euro-American contexts are frequently criticised in anthropological literature on obstetrics, midwifery, and health care for their large degree of medicalisation and technologisation (cf. e.g. Cooley, 2008; Bradby \& MurphyLawless, 2002; Tremayne, 2001; Murphy-Lawless, 1996; Oakley, 1984, 1994, esp. pp. 124- 
138). ${ }^{4}$ Granted, these are not the only aspects of human existence that have experienced increased medical scrutiny. ${ }^{5}$ However, a comparison of ethnographic data demonstrates a wide array of attitudes to pregnancy and childbirth without locating these phenomena in the framework of health and illness (see e.g. Jordan, 1993). Interestingly, these attitudes towards gestation and labour choices often change from childbirth to childbirth in a non-linear manner, for instance when a homebirth is followed by a hospital birth, which in turn is followed by a homebirth with a midwife present (Bradby, 1999, 2002).

So what about Bolivia, then? Bolivia's maternal mortality rates remain elevated by international standards, despite implemented government programs aimed at monitoring pregnancy and infancy, such as the Juana Azurduy stipend (Bono Juana Azurduy) or the aforementioned Universal Mother-Infant Insurance, SUMI (cf. Moloney, 2010, p. 1955; Bradby, 1999, 2002, p. 168). ${ }^{6}$ According to a World Health Organisation (WHO) report analyzing data from 1980 to 2008, the Maternal Mortality Ratio (MMR) for Bolivia decreased from 547 deaths (with 344 in urban areas and 845 in rural areas per 100,000 births) in 1980 to 439 (276-666) in 1990, to 269 (168-413) in 2000, and finally down to 180 (110-284) in 2008

\footnotetext{
${ }^{4}$ For a general overview of medicalisation see e.g. Tiefer (1994); Martin (2001); and Kleinman (1980, 1995). The history of medicalisation of women's conditions, including pregnancy, was addressed by e.g. Stone (2009, pp. 4153); Rattner (2008); Lorber (2000); Manger (1992, pp. 257-78); Knibiehler and Fouquet (1983, esp. pp. 235-254); Ehrenreich and English (1973); and Gélis (1991). Literature review of medicalisation of pregnancy can be found in Katz Rothman (2004, 2007); Simons, Rothman and Norman (Eds.) (2007); Kaufman and Morgan (2005); Fox and Worts (1999, esp. pp. 327-332); Ginsburg and Rapp (1991); Martin (2001, esp. pp. 54-67); and Young (1982). Medicalisation of childbirth in particular was discussed at length in van Teijlingen et al. (Eds.) (2004). An extensive, in-depth analysis of obstetric care may be found in e.g. Rapp (1999), Murphy-Lawless (1996), Hahn (1995, esp. pp. 209-233); Kolker and Burke (1994); and Gélis (1991). For a discussion of midwifery as authoritative knowledge, see e.g. van Teijlingen et al. (Eds.) (2004); Marland and Rafferty (1997); Davis-Floyd and Sargent (Eds.) (1997); Davis-Floyd and Davis (1996); Mulhall (1996); Gaskin (1996); Marquez and Pacheco (1964). Critique of the consumerist aspect of medicalisation of motherhood may be found in a volume edited by Taylor, Layne and Wozniak (Eds.) (2004). A feminist look on the phenomenon of motherhood, including pregnancy and childbirth is offered by Glenn, Chand and Forcey (Eds.) (1994).

${ }^{5}$ Foucault $(1978,1979)$ offers a seminal analysis of the control of bodies, and women's bodies in particular, in Euro-American culture, science, and biomedicine.

${ }^{6}$ Kwast (1980, p. 251) maintains that the lack of success of such campaigns should be ascribed to the concept of pregnancy as a natural state rather than a medical condition. Clearly, effective healing depends on the choice of medical system and a degree of shared knowledge between the healer and the patient (King 1998,p. 22; Bastien, 1994). Additionally, Cadden observed that the treatment needs to take place "within the expectations and practices of the patient's family" (1993, p. 5).
} 
(Hogan et al., 2010). Curiously, another WHO Mortality Country Fact Sheet puts the Bolivian MMR at 420 in 2006 (WHO, 2006). Yet another estimate, prepared with UNICEF in 1990, calculated a higher MMR at 650 rather than 439 (WHO \& UNICEF, 1990). Difficult labour is mentioned as one of the main reasons for going to hospital to give birth. In such cases, although a biomedical doctor's decision to perform a caesarean section might be motivated by the perceived convenience of shortening a particularly long-lasting labour, such surgery performed on an already exhausted woman has a higher maternal mortality incidence than regularly scheduled C-sections. At times, despite difficult, prolonged labour and a local midwife's recommendation of going to hospital, the cost of transportation to a medical centre is such that the family decides against it (Maupin 2008, pp. 374-376). ${ }^{7}$ This data, however, varies significantly across the country's departmental territories as well as its rural and urban areas. Unsurprisingly, like almost everywhere in the world, maternal mortality is higher in rural areas (Galindo Soza, 2010). Among the Bolivian departments, Santa Cruz de la Sierra stands out with one of the lowest maternal mortality rates and the most comprehensive health service coverage (INE, 2012, PNUD, 2007). Such excellent statistics in comparison to the rest of the country are broadly due to the fact that a large majority of the department's population lives in urbanised areas, if not in the departmental capital itself, then in the nearby towns of Cotoca, Camiri, Warnes, Montero, or La Guardia, to mention the largest.

There is no unified health care for all Bolivians (Ley de prestaciones de servicios de salud integral del Estado Plurinacional de Bolivia, The law of integrated health services provision of the Plurinational State of Bolivia, 2013). Instead, multiple social groups can enjoy the privileges of various existing types of medical insurance if they satisfy certain conditions, e.g. being over 60 years old, being a woman of reproductive age who desires offspring (ibid.).

\footnotetext{
${ }^{7}$ According to WHO estimates, traditional medicine is the default health care system of approximately 80 percent of inhabitants of developing countries. It frequently proves to be a more efficient therapeutic method as well as more cost effective (Bussmann \& Glenn, 2010,pp. 1-2).
} 
Such is the case of women during pregnancy and for six months following childbirth. At present, all pregnant women can access free health care (which extends to their children up to the age of five) in state-run hospitals, where appointments are made on a first come, first served basis. This caveat sometimes makes it impossible for a woman to benefit from this governmentoffered privilege. Quite frequently, it is not possible for the woman to leave her older children in the care of someone else; sometimes babies are too young to be left in nurseries and kindergartens (which are neither free nor easily accessible). Single mothers often have to devote an entire working day for the doctor's appointment, which deprives them of a whole day's wages. Alongside these demands of everyday realities, there are also emotional considerations: some women, especially those from underprivileged social groups, can often experience a great deal of anxiety during such visits. For instance, such women can feel physically uncomfortable due to the nature of the exam - especially if performed by a male doctor - as well as emotionally stressed, as a result of different communication styles between the doctor and the woman. This can occur when specialised vocabulary is used while explaining the condition to the woman, and can be even further compounded if the specialist speaks in Spanish, when the woman might be more comfortable communicating - and have higher proficiency - in one of the indigenous languages spoken in Bolivia.

There are significant differences concerning approaches to reproductive health within Bolivia. Generally speaking, people from rural areas are much less adventurous with respect to using various methods of contraception or consulting the biomedical specialists. Among methods of contraception used in Bolivia, IUDs, contraceptive injections of subdermal implants, are more popular among the emerging middle class as well as among the part of the population with more years of formal schooling, who are more likely to live in urban areas (Coa, 2006; Página Siete, 2015). This difference is also visible across genders: women display more interest in learning about their possibilities when it comes to having - or, indeed, not 
having - children (Paulson \& Bailey, 2003). With regards to contraception and beyond, women from urban areas are privileged in the number of solutions at their disposal: in addition to the state-run hospitals, there are also NGO-managed and private health clinics, church-run hospitals (which are not supportive of either abortion or contraception), and, of course, practitioners of traditional medicine. Nonetheless, the decisions of choosing one specialist or hospital over another is dictated by a combination of factors, some of which are beyond the woman's control: availability of affordable transport, proximity to the hospital, financial situation, former experiences, friends' or family members' advice, level of fear and anxiety about going to a biomedical facility, number of children she already has, possible previous caesarean sections, desire to have more children, and, possibly above all, whether or not she believes she needs to see a biomedical specialist. With all these influencing factors, I would like to argue that the implementation of a national health insurance system designed particularly for pregnant women and young children tipped the scale in favour of biomedicine.

The introduction of SUMI affected pregnant women's choices in a fundamental way. Prior to this, each appointment at a health clinic meant additional financial strain. Despite the fact that the fees in the cheapest hospitals are not very high by Euro-American standards, they may still cost as much as a solid, home-cooked meal for a large family. Receiving a prescription also incurs additional costs since the Bolivian pharmaceutical industry is not well developed and a large majority of medications, including the most commonly used analgesics, such as paracetamol and ibuprofen, are imported from neighbouring countries, which translates into relatively high prices. Therefore, to a woman who has successfully survived a number of pregnancies and births, antenatal checks may seem - quite logically - like an unnecessary expense. SUMI changed that drastically: suddenly, not only were ante- and postnatal appointments free of charge, they might also become a way of receiving small - but regular amounts of money. 
I would like to argue that the availability of free medical care for pregnant women, especially with the recent support of financial incentive, significantly influenced the way Bolivian women think about pregnancy, especially in urbanised areas. The level of authority and the kind of privileged knowledge that doctors are ascribed, especially from the viewpoint of people without many years of formal education, combined with the state supported system of health insurance - which clearly marks pregnancy as a medical condition - all combine to pressure women into sharing this view of pregnancy too. Curiously, although under the proindigenous leadership of president Evo Morales, the Bolivian government now includes Viceministerio de Medicina Tradicional e Interculturalidad (Vice-Ministry of Traditional Medicine and Interculturality), and the 2009 Political Constitution of the State officially recognised medical systems other than biomedicine, they offer limited protection of these medical traditions in the face of financial incentives of SUMI's powerful push towards a biomedical approach uptake.

\section{Traditional midwifery and hospital birth}

In traditional Andean medicine, it is the partera, midwife, who leads the woman through her pregnancy. She is knowledgeable and attentive, she is able to recognise trouble by checking the pulse on the woman's wrists, she puts her ear to the abdomen to hear the foetus's heartbeat, and she can massage a breached foetus into the proper birthing position. ${ }^{8}$ With increasing access to biomedicine, traditional midwives frequently attend courses of midwifery taught by biomedical doctors, where they were informed about techniques to make childbirth more hygienic by using sterilised materials and washing their hands thoroughly with soap before delivering the baby. The encouragement towards these techniques would come in the form of a sterile birthing kit, given to each midwife who completed the course, accompanied by a printed

\footnotetext{
${ }^{8}$ In fact, this last skill was fondly talked about among my informants as it prevented the necessity for a frequently feared caesarean section.
} 


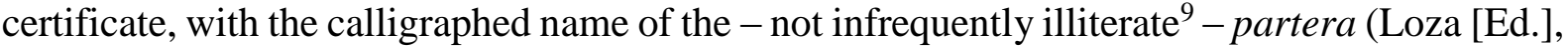
2012).

There are very few midwives in the city of Santa Cruz de la Sierra, and even fewer still practising. ${ }^{10}$ The statistics for childbirth attended by specialised professionals in the city of Santa Cruz (which include biomedically-trained midwives) reach over 97 percent (INE, 2012). During my research I managed to locate three midwives, only one of whom still attended births. Doña Selena ${ }^{11}$ lived in a district located to the north-east of the city centre. It was a relatively recently urbanised zone, where previously only the main roads, corresponding with the minibus routes, were paved. The most remote houses were located about 25 minutes away from the nearest mini-bus stop and then it took another good 40 minutes on public transport to reach the nearest public hospital. Some women in labour would not make it in time. They were the ones who would seek Doña Selena's help.

Doña Selena is one of the parteras who completed a biomedically-oriented course and became certified. Additionally, she learnt from other local practicing traditional midwives, most of whom were from the lowlands. In the past, she would deliver about 30 babies a month these days she only attends one or two births in that same period. In theory, births attended by certified midwives (both traditional and biomedical) qualify as "institutional delivery" and, by the same token, for the Juana Azurduy stipend. However, the midwife is obligated to produce a certificate for the woman. Doña Selena does not supply such certificates. This is one of the reasons why Santa Cruz women who qualify for the Bono are more likely to make an effort to deliver in a state-run hospital. Another is the urbanisation of the area of the city where Doña

\footnotetext{
${ }^{9}$ Women are more likely to be illiterate than men, especially in rural areas, where traditional midwives are more likely to be found, where the analphabetism levels for women over 30 exceed $70 \%$ (INE, 2012).

${ }^{10}$ This is very different from the Andean zone, where traditional midwives issue birth certificates and are relatively easy to find. During a stay in La Paz I went for a visit to the offices of the Vice-Ministry of Traditional Medicine and Interculturality on the day where traditional midwives were having a reunion. I counted seventeen - and I was not even looking for them on that day!

${ }^{11}$ All names have been changed.
} 
Selena lives, which is a significant factor as the hospital is now within easier reach for many people in the surrounding area. Additionally, there are further factors at play: the availability of medical insurance, the potential advantages of hospital birth for mother and the baby, as well as the idea that labour and childbirth specifically require medical attention.

It is very important to emphasise that this situation is not uniform in Bolivia. There is much more resistance towards giving birth in the hospitals in Andean zones on the one hand, and, on the other, in rural areas. ${ }^{12}$ Multiple authors report a high level of reluctance towards hospital delivery - women are frequently anxious about being attended by male doctors, about the low temperatures in the hospital rooms which are believed to cause illnesses, and caesarean sections (Bradby, 1999, pp. 293, 296-9; Larme, 1998, p. 1009; cf. Platt, 2002, p. 131; Bourque \& Warren, 1981,p. 90-95). The city of Santa Cruz de la Sierra may constitute a special case in terms of the almost complete uniformity with regards to receiving biomedical attention in childbirth. This homogeneity, however, may turn out to be superficial if women's motivations are scrutinised. While a large majority consciously direct their steps to the biomedical institution at the end of pregnancy, their decision-making processes are by no means uniform, and neither are their expected nor their actual outcomes.

An analysis of statistics concerning aspects of pregnancy and childbirth in Bolivia points to the fact that the introduction of a national maternal health insurance covering such situations was a successful decision with regards to health service strategies and the concomitant increase of availability of biomedical services. Its first version, Seguro Nacional de Maternidady Niñez, was introduced in 1994, replaced in 1998 by Seguro Básico de Salud, and finally by the current SUMI in 2003 (PNUD, 2007, p. 97; Galindo Soza, 2010, pp. 14-17). Maternal mortality dropped by almost 50 percent between 1990 and 2003 and continues to decrease (PNUD, 2007), which is undeniably a positive change. However, lower maternal mortality rates are not entirely

\footnotetext{
${ }^{12}$ According to the latest census, at a national level, women from rural areas are five times less likely than women living in urban areas to give birth in hospitals (INE, 2012).
} 
the result of the wider availability of national insurance. Decreased infant mortality rate is also linked with women having fewer children. ${ }^{13}$ And fewer births translate into a lower maternal mortality rate as risk increases with each pregnancy. ${ }^{14}$ Furthermore, in 2009, the government of Bolivia introduced the Bono Juana Azurduy, a small stipend paid to the women who fulfil a number of caveat-ridden conditions. Any woman who wants to claim it should have her first antenatal visit before the end of the first trimester of pregnancy, followed by three check-ups at bimonthly intervals between months four to nine. Childbirth must take place at a state-run or other certified hospital or must happen in the presence of a certified midwife. Within seven days of the birth, the woman and the baby should have their postnatal check-up. Following that, the child should be seen by the doctor every two months until he or she is two years old. At present the stipend amounts to Bs. 1820 in total (approximately US\$280) and can be claimed through regular doctor's appointments during a period of up to 33 months. Each antenatal visit is worth Bs. 50, childbirth at a state hospital and postnatal examination are valued at Bs. 120, while each bimonthly visit with the baby awards the woman Bs. $125 .{ }^{15}$ The right to receive the stipends can be relatively easily lost by missing two consecutive appointments during the child's first two years of life, by prior loss of the right to the Juana Azurduy stipend due to missed appointments, by becoming pregnant sooner that three full years after the birth of the last child, and by lying about one's socio-economic status.

In the context of Santa Cruz, where hospital birth is virtually the only option, pregnant women are active in the plans they make for the delivery. These plans are influenced, very importantly, by their own (or their friends' or relatives') previous birth experiences, financial situation, and immediate labour circumstances, e.g. location. Private clinics or hospitals are

\footnotetext{
${ }^{13}$ See e.g. Bongaarts (2009).

${ }^{14}$ WHO guide to managing maternal and child health programmes states that "[p]regnancy and childbirth risks are increased when a woman becomes pregnant at below 18 years of age or above 35 years of age, during the first and after the fourth childbirth, when birth spacing is less than two years or when pregnancy is unwanted" (1997, p. 2). 15 These values have not changed for the last 10 years (Ministerio de Salud y Deportes, 2006; UNFPA, 2016) even though minimum wages in the same period increased by $370 \%$ from Bs. 500 to Bs. 1,850 (Lazcano, 2016).
} 
generally considered to offer better services than state-run hospitals. Because only a small part of the population qualifies for national health insurance of some sort, potential patients have to pay for a doctor's appointment, which is likely to influence choices they make. In other words, a negative experience of childbirth in a state-run hospital may result in choosing an affordable private clinic for a subsequent birth. This decision has further potential advantages, namely, the availability of anaesthesia on request or a planned caesarean section. The percentage of Csection deliveries in the department of Santa Cruz is over 38 percent (INE, 2012), which is more than double the 15 percent rate, recommended by the WHO until June 2010 (WHO, 2010). ${ }^{16}$ A young doctor employed by one of the city-centre clinics estimated that between 80 and 90 percent of pregnant patients undergo a caesarean section in that clinic. The remaining 10 to 20 percent of patients are mostly Bolivian Mennonites, whose convictions do not encourage elective surgeries. ${ }^{17}$ Another doctor mentioned the convenience of scheduling a C-section from the point of view of the professional in terms of the time necessary to deliver the baby (operations can be scheduled and are of shorter duration than average childbirth by forces of nature) but also with regards to the remuneration for the procedure - vaginal delivery costs three times less than a surgery. ${ }^{18}$

I would like to illustrate the complexity of the intersection of reproduction and medical choices in Santa Cruz de la Sierra with an example of María's life story that demonstrates how women actively negotiate what happens to them as much as they can in their circumstances. She is a second generation migrant - her mother was from the department of Oruro in the southwest of Bolivia and spoke both Quechua and Aymara in addition to Spanish. María was born

\footnotetext{
16 The WHO suspended this recommendation and its handbook for Monitoring Emergency Obstetric Care states that "[u]ltimately, what matters most is that all women who need caesarean sections actually receive them" (WHO, 2010, p. 25).

${ }^{17}$ Eduardo Rojas, personal communication.

${ }^{18}$ Dr RubénVaca Vaca, personal communication. At the time of my research in 2013 Dr Vaca Vaca was the manager of Red Salud Este (Eastern Health Network) in the city of Santa Cruz, delivering state-funded biomedical services to approximately 350,000 people in the city.
} 
in Santa Cruz and only speaks Spanish, but with a slight Andean accent. Her facial features also point to her Andean origin, but she usually dresses like a camba, person native to Santa Cruz, in leggings and tight tank tops. She is a mother of four: two daughters, Alejandra and Patricia, born in 1997 and 2000 and two sons, Fernando and Juan, born in 2008 and 2012. Prior to her first pregnancy she studied law at the Santa Cruz state university, but she never graduated, failing to finish writing her thesis. She had already been married for five years before she became pregnant for the first time. Because María and her husband had been trying for such a long time, they suspected that perhaps one of them could not have children at all. Following María's mother's advice, they went to pray in a church where masses were celebrated in Quechua. María became pregnant with Alejandra two months later. The second daughter came relatively soon and with two small children to take care of, it was extremely difficult for María to find stable employment. When Alejandra and Patricia were finally old enough to be left on their own, María became pregnant again. When asked, she said that she did not want to have more children and 8 months after she gave birth to her last son Juan, she went to Marie Stopes International clinic for women, in order to have a subdermal contraceptive implant inserted. ${ }^{19}$

María gave birth to her first baby in a state-run hospital. It was a regular vaginal delivery and she was lucky enough for it to be a relatively quick. Despite this fact, María remembered it as a very traumatic event. With a voice trembling with emotions, at times with tears in her eyes, she recounted what happened on that day: "I was disoriented, nobody told me what was going to happen to me, I wasn't ready for any of it. I heard screams and after a while I realised that they were women giving birth, and then I realised that I am one of them... that I will be screaming like that real soon. The doctor was muy bruto, very rough/brusque, he would put his

\footnotetext{
${ }^{19}$ Marie Stopes International is a non-for-profit organisation specializing in sexual and reproductive health. It has a number of clinics in Bolivia, including three in the city of Santa Cruz de la Sierra, and is known for offering solutions to unwanted pregnancies and a wide spectrum of modern contraceptive options, from mechanical to hormonal, at affordable prices. In Santa Cruz, all three clinics are located near major markets, which is extremely convenient for women, who constitute the majority of vendors.
} 
cold hand down there to check if I was dilated. He made comments and rude jokes about my pain." When María found out that she was pregnant for the second time, she was determined not to return to that same hospital. With the help of her mother and her husband, she started saving up money to give birth in a local private clinic despite the fact that she qualified for a free delivery in a state-run hospital. When the labour pains came, she went to the clinic and even though she remembered her second birth as longer and more painful, she was much more at peace with the way she was treated. "The nurses, they talked to me to calm me down, I didn't feel so alone," said María. With the third pregnancy, as the ultrasound revealed the sex of the foetus as male, it was María's husband who insisted on childbirth in a private clinic. "So that nothing happens to my only son,” he argued. It was 2008 but she remembered having been treated badly in the first hospital and despite the fact that she had heard about changes in staterun health institutions and constant money problems in her family, María still preferred to not risk it.

The shift in her decision-making came during her last pregnancy. In 2011, when María became pregnant with Pablo, she qualified for the Juana Azurduy stipend. In fact, she was quite relieved that the financial strain of the pregnancy would not be as serious this time. She attended her antenatal checks religiously, and made arrangements for the hospital birth in the state-run hospital nearest to her household. There were some obstacles in the process as María's mother moved out to help Esther, María's younger sister, who had recently given birth, which put a strain on the household economy. However, María was resolved to put herself in the hands of the doctors in the state-run hospital, silently hoping that things had changed in the last 14 years. At the end of the ninth month the labour pains came. As they became more frequent and it was time to go to hospital, María and her husband got into a taxi and headed for hospital. Unfortunately, a serious power outage in a large part of the neighbourhood thwarted their plans. Since the contractions were becoming more frequent, they went to a second state-run hospital, 
which unfortunately was also without electricity. At that point María threatened to give birth in the street if they did not go to the nearest private clinic, which had a generator, where the baby could be safely delivered.

There were multiple consequences to this turn of events. The most immediate one constituted the necessity of coming up with the money to pay for the birth at a private establishment. Furthermore, the right to the Juana Azurduy Stipend was lost: it is only awarded to the most economically underprivileged, therefore, women who can afford give birth in private clinics are automatically excluded from this category, in addition to the fact that these clinics do not offer the appropriate certificates for mothers to claim the stipend. That power cut deprived María and her newborn son, as well as the rest of the family, of a way of supplementing their already slender income with a small amount of extra cash. The national insurance for mothers and infants still allows her to receive postpartum check-ups as well as to take her infant son for doctor's appointments, but she is much less likely to do it if there is no financial incentive that could at least partially offset the effort of going to the doctor in terms of transportation costs and the time spent on waiting in queue at the hospital. Frequently, when women do not qualify for the stipend and their new-born seems healthy, they refuse to take them to hospitals on the grounds of not wanting to bring the baby to an environment full of sick babies.

The history of María's pregnancies shows that biomedical attention was not an issue of major importance in the choices she made for each birth. In fact, it remained beyond any consideration at all. Doubtless, it had - at least partially - to do with the fact that her labours were mostly uneventful in terms of complications. On the other hand, she did take into account the quality of service provided by the nurses (but not doctors) as well as the price of the service. Additionally, María focused on her own wellbeing much more than on the baby's while planning the delivery. Rather than suggesting that she is an uncaring mother, it points to her 
recognizing that the comfort of the woman during childbirth is included in the appropriate care of the newborn. Furthermore, María's decisions in her subsequent pregnancies point to the fact that priorities change depending on social and economic circumstances as well as on individual experience.

In many ways, María is not an average Andean migrant woman. She went to university and she does not have to maintain her family on her own. And yet, the decisions she made about each of her pregnancies are similar to the ones I learnt about from other women I interviewed. They tended to base their decisions on their own experiences as well as the advice of their friends and relatives. Sometimes, public advertisements can encourage a woman to choose one private clinic over another - in Santa Cruz private clinics often advertise on the radio by announcing their price lists of the most popular laboratory tests and operations, including Csections. Public information campaigns also play a certain role in women educating themselves about pregnancy and baby care. During my fieldwork I heard a number of short radio broadcasts on the benefits of breastfeeding and the colostrum in particular. Some Andean women do not offer colostrum to the baby, the act of which symbolically teaches the child about scarcity (Bradby, 2002, p. 89). The broadcast had the form of a conversation between a male doctor and a new mother, who spoke with a rural Andean accent. The doctor was informing the woman of the importance of feeding the baby with colostrum and spreading a vision of unspeakably terrible consequences should she not follow his advice. The woman responded in a guilt-ridden voice “¡Ay, doctor, no supe yo!” (Oh, doctor, I didn’t know!) The dialogue was quite repetitive, which is not unusual for advertisements in Bolivia, but successfully reinforced the idea of biomedical (male) doctors who hold the key to knowledge.

It is indeed a prominent aspect of medical professionals in Bolivia (and probably in many other places as well) - biomedical specialists tend to be authoritative and are considered 
to have the authority. ${ }^{20} \mathrm{~A}$ brief examination of printed materials about female reproductive and sexual rights in Bolivia illustrates it well. Those tastefully colourful and beautifully edited booklets, prepared by the Bolivian branch of the United Nations Populations Fund, are abundantly illustrated with rather infantilised and repetitive images (UNFPA \& FCI/Bolivia, 2011). In them, all doctors - who in this context are either obstetricians or gynaecologists - are male, while all the nurses, many of whom sport impressive cleavages, are female. ${ }^{21}$ Outside of the doctor's coat, men appear very rarely (once, to be precise). Women, on the other hand, are very frequently accompanied by children and are dressed either in complete traditional clothing or outfits incorporating traditional elements - curiously, the only woman portrayed wearing trousers was a specialised nurse, who also wore a lab coat and was using a stethoscope to listen to the foetal heartbeat. Despite the fact that the brochures mention traditional midwives, they are not present in the drawings. The drawings portray pregnant women who seek biomedical doctor's appointments in hospitals and clinics as well as women smiling while holding their swaddled babies. This imagery reinforces the message that pregnancy should be supervised by biomedical professionals and suggests that they can guarantee positive outcomes.

\section{Conclusion}

One of the implicit assumptions behind introducing the national maternal health insurance - SUMI in the case of Bolivia - is that it will benefit everyone. The universal coverage, i.e. availability to all pregnant women and new mothers, in principle suggests that all pregnant women and new mothers should, or even must, take advantage of it. After all, the state is unlikely to stand behind a program which could prove destructive to people's reproductive lives. Additionally, even though it is advertised as free insurance, it is not effectively free. Women who perform hourly-paid jobs face a difficult decision: whether or not to give up a

\footnotetext{
${ }^{20}$ See e.g. Cueto\& Palmer (2015), Zulawski (2007).

${ }^{21}$ It is an interesting choice of gender in the light of the fact that 60 percent of Bolivian women who actually go to a gynaecologist prefer a female doctor over a male doctor (El Deber, 2012).
} 
day's wages (and possibly future earning possibilities) and spend money on transport (or even medication), not to mention the stress of waiting for an appointment with a possibly unpleasant doctor. It is understandable, then, that SUMI in practice may not seem as enticing from the point of view of women.

Furthermore, Bono Juana Azurduy attracts the most economically disadvantaged, that is, those who actually qualify for it. They are the same women who are the most likely to seek to deliver in the presence of a traditional midwife rather than a culturally insensitive doctor. Thus, the existence of the stipend steers them towards biomedical treatment of gestation. On the other hand, as discussed above, it is fairly easy to lose the privilege or not to qualify for it in the first place. Once the stipend becomes unavailable, the landscape of possibilities is altered - and may include a home birth with a midwife in a remote neighbourhood, a C-section on demand in a private clinic or a vaginal delivery in a hospital of choice. Few of the women I interviewed actually succeeded in claiming more than 60 percent of the total instalments touted by the program. Among the obstacles they mentioned were: late discovery of pregnancy, reluctance towards giving birth in a state-run hospital, or missing two consecutive check-up appointments with the baby. Therefore, it is once again clear that the Bono in practice is not as attractive or as available as it is claimed to be and most Andean migrant women in the city of Santa Cruz de la Sierra have been delivering their babies in hospitals for a number of decades, financial incentives notwithstanding. ${ }^{22}$

At whom are such programs aimed, then? It is somewhat paradoxical that the government, on the one hand, recognises traditional medicine in the constitution, creating a vice-ministry for it, and, on the other hand, simultaneously designs a program which obviously foregrounds biomedicine. The impact of SUMI becomes clearer, however, when the motivations behind the national health insurance for pregnant women and children are

\footnotetext{
${ }^{22}$ Data from the last census suggests that between 70-90 percent of migrant women in Santa Cruz aged 20-60 had their last childbirth in a biomedical facility (INE, 2012).
} 
examined through the lens of Human Development Reports and, more recently, the Millennium Goals (in particular, Goal 4: Reduce Child Mortality and Goal 5: Improve Maternal Health) (Millennium Project, 2006). Both of these collections of statistical data consider maternal and infant mortality as markers of development and well-being. Haemorrhages and infections are two main reasons for maternal mortality in Bolivia; together they account for 50 percent of cases (UNFPA, 2011, p. 37). Both complications are more likely to be treated effectively in biomedical institutions, which helps to explain the general orientation of the state-designed health programs. While I do not wish to diminish the significance of lowered maternal mortality for individual Bolivian women who have survived thanks to biomedical intervention, it is not insignificant to point out beyond their individual wellbeing, the political implications of the statistics these living mothers make up, positioning Bolivia as a state that advances, by taking care of women and children's health.

In the case of Santa Cruz de la Sierra, it is clear that the biomedical attention during delivery is responsible for lowering maternal mortality, which leads the Bolivian statistics to fare slightly better in world rankings. However, when women's choices about place of childbirth are scrutinised, it is also clear that a large part of this biomedical attention was financed by the women themselves, and not by the state through national maternal insurance. Migrant women in Santa Cruz by and large deliver their babies in hospitals because other options, such as home birth with a traditional midwife, have become virtually unavailable. Perhaps the disappearance of traditional midwives, rather than state-offered options of receiving medical attention, constituted a much more influential factor in the general movement of women towards hospital childbirth. It seems, therefore, that SUMI, the Universal Mother-Infant Insurance, may have a prominent political dimension, which obscures its socio-medical function. Should it not be the other way round?

Acknowledgements: I would like to thank Łukasz Krokoszyński, Katarzyna ByłówAntkowiak, Máire Ní Mhórdha, Christopher Hewlett, and Meera Burgess for comments on 
earlier drafts of this paper. I would also like to express my gratitude for the insightful comments of the anonymous reviewers.

\section{References}

Bastien, J. W. (1994). Collaboration of doctors and nurses with ethnomedical practitioners. World Health Forum, 15, 133-137.

Bernard, H. R. (2011). Handbook of Methods in Cultural Anthropology. London: Sage Publications.

Bongaarts, J. (2009). Human population growth and the demographic transition. Philosophical Transactions of the Royal Society B: Biological Sciences, 364(1532), 2985-2990.

Bourque, S. C. \& Warren, K. B. (1981). Women of the Andes: Patriarchy and social change in two Peruvian towns. Ann Arbor: University of Michigan Press.

Bradby, B. \& Murphy-Lawless, J. (2002). Reducing maternal mortality and morbidity in Bolivia: Appropriate birth practices in the formal and informal sectors of perinalatal care. La Paz: ILCA.

Bradby, B. (1999). Will I return or not? Migrant women in Bolivia negotiate hospital birth. Women's Studies International Forum, 22(3), 287-301.

Bradby, B. (2002). Local Knowledge in Health: The Case of Andean Midwifery. In H. Stobart $\&$ R. Howard (Eds.), Knowledge and Learning in the Andes: Ethnographic perspectives (pp. 166-193). Liverpool: Liverpool University Press.

Bussmann, R. W. \& Glenn, A. (2010). Medicinal plants used in Northern Peru for reproductive problems and female health. Journal of Ethnobiology \& Ethnomedicine, 6(30), 1-12.

Cadden, J. (1993). Meanings of sex difference in the Middle Ages: Medicine, science, and culture. Cambridge: Cambridge University Press.

Coa, R. (2006). Dinámica de la Anticoncepción en Bolivia y su interrelación con factores socioeconómicos 1989-2003. La Paz: ST-CODEPO.

Cooley, S. (2008). Bringing a body to bear in the Andes: Ethnicity, gender, and health in highland Ecuador. Michigan Discussions in Anthropology, 17(1), 132-160.

Cueto, M. \& Palmer, S. (2015). Medicine and public health in Latin America. New York: Cambridge University Press.

Davis-Floyd, R. E. \& Davis, E. (1996). Intuition as authoritative knowledge in midwifery and homebirth. Medical Anthropology Quarterly, 10(2), 237-269. 
Davis-Floyd, R. E. \& Sargent, C. F. (Eds.). (1987). Childbirth and authoritative knowledge. Cross-Cultural Perspectives. Berkley: University of California Press.

Ehrenreich, B. \& English, D. (1973). Complaints and disorders: The sexual politics of sickness. London: Writers and Readers Publishing Cooperative.

El Deber. (2012). Superá el miedo al ginecólogo. 25/07/2012. Retrieved from http: //www.eldeber.com.bo/supera-el-miedo-al-ginecologo/120724213726.

Finerman, R. (2004). Saraguros. In C. Ember \& M. Ember (Eds.), Encyclopedia of medical anthropology: Health and illness in the world's cultures (pp. 937-947). New York: Kluwer Academic/Plenum Publishers.

Foucault, M. (1978). The history of sexuality, Volume I: An introduction. Transl. by R. Hurley. New York: Pantheon.

Foucault, M. (1979). Discipline and punish: The birth of the prison. Transl. by A. Sheridan. New York: Vintage.

Fox, B. \& Worts, D. (1999). Revisiting the critique of medicalised childbirth: A contribution to the sociology of birth. Gender \& Society, 13(3), 326-346.

Galindo Soza, M. (2010). El Progreso Invisible. El Seguro Universal Materno Infantil. La Paz: Fundación Milenio.

Gaskin, I. M. (1996). Intuition and the emergence of midwifery as authoritative knowledge. Medical Anthropology Quarterly, 10(2), 295-298.

Gélis, J. (1991). History of childbirth: Fertility, pregnancy and birth in early modern Europe. Transl. by R. Morris. Cambridge: Polity.

Ginsburg, F. \& Rapp, R. (1991). The politics of reproduction. Annual Review of Anthropology, 20, 311-343.

Glenn, E. N., Chang, G. \& Forcey, L. R. (Eds.). (1994). Mothering: Ideology, Experience, and Agency. New York: Routledge.

Hahn, R. A. (1995). Sickness and healing: An anthropological perspective. New Haven: Yale University Press.

Hogan, M. C. et al. (2010). Maternal mortality for 181 countries, 1980-2008: A systematic analysis of progress towards Millennium Development Goal 5. Lancet, 375(9726), 1609-1623.

INE. (2012). Censo de Población y Viviendas 2012. La Paz: INE.

Jordan, B. (1993). Birth in four cultures. A crosscultural investigation of childbirth in Yucatan, Holland, Sweden, and the United States. Revised and expanded by Robbie Davis-Floyd. Prospect Heights, IL: Waveland Press, Inc. 
Katz Rothman, B. (2004). Motherhood under capitalism. In J. S. Taylor, L. L. Layne \& D. Wozniak (Eds.), Consuming motherhood (pp. 19-30). New Brunswick, NJ: Rutgers University Press.

Katz Rothman, B. (2007). Labouring now: Current cultural constructions of pregnancy, birth, and mothering. In W. Simonds, B. Katz Rothman \& B. Meltzer Norman (Eds.), Labouring on: Birth in transition in the United States (pp. 29-93). New York: Routledge.

Kaufman, S. R. \& Morgan, L. M. (2005). The anthropology of the beginnings and ends of life. Annual Review of Anthropology, 34, 317-341.

King, H. (1998). Hippocrates' woman: Reading the female body in ancient Greece. London: Routledge.

Kleinman, A. (1980). Patients and Healers in the Context of Culture: An Exploration of the Borderland between Anthropology, Medicine, and Psychiatry. Berkeley: University of California Press.

Kleinman, A. (1995). Writing at the Margin Discourse between Anthropology and Medicine. Berkeley: University of California Press.

Knibiehler, Y. \& Fouquet, C. (1983). La femme et les médcins. Analyse historique. Paris: Hachette.

Kolker, A. \& Burke, B. M. (1994). Prenatal testing: A sociological perspective. Westport: Bergin and Garvey.

Kuberska, K. (2016). Sobreparto and the lonely childbirth: Postpartum illness and embodiment of emotions among Andean migrants in Santa Cruz de la Sierra, Bolivia. Etnografia. Praktyki, Teorie, Doświadczenia, 2, 47-71.

Kwast, B. E. (1980). Comments. In R. H. Philpott (Ed.), Maternity services in the developing world (p. 251). Proceedings of the Seventh Study Group of the Royal College of Obstetricians and Gynaecologists.

Larme, A. C. \& Leatherman T. (2003). Why sobreparto? Women's work, health and reproduction in two districts of southern Peru. In J. D. Koss-Chioino, T. Leatherman, C. Greenway (Eds.), Medical pluralism in the Andes (pp. 191-208). New York: Routledge.

Larme, A. C. (1993). Work, reproduction, and health in two Andean communities (Department of Puno, Peru). Working Paper No. 5. Production, storage, and exchange project, University of North Carolina Department of Anthropology, Chapel Hill, NC. 
Larme, A. C. (1998). Environment, vulnerability and gender in Andean Ethnomedicine. Social Science \& Medicine, 47(8), 1005-1015.

Lazcano, M. (2016). El salario mínimo subirá a Bs 1.805 y el haber básico aumentará en 6\%, La Razón. 27/04/2016. Retrieved from http://www.larazon.com/index.php?_url=/economia/Acuerdo-salario-minimo-subira-haber_basicoaumentara_0_2480151989.html.

Leatherman, T. (1998). Changing biocultural perspectives on health in the Andes. Social Science \& Medicine, 47(8), 1031-1041.

Leatherman, T. (2005). A Space of Vulnerability and Health: Biocultural Vulnerability in Poverty and Political-Ecology Analysis. Ethos, 33(1), 46-70.Ley de prestaciones de servicios de salud integral del Estado Plurinacional de Bolivia. (2013). Gaceta Oficial de Bolivia, 30/12/203.

Lorber, J. (2000). Gender and the social construction of illness. Walnut Creek, CA: Altamira Press.

Loza, C. B. \& Álvarez W. (2011). Sobreparto de la mujer indígena, saberes y prácticas para reducir la muerte materna. La Paz: INBOMETRAKA.

Loza, C. B. (2008). El laberinto de curación. Itinerarios terapéuticos en las ciudades de La Paz y El Alto. La Paz: ISEAT.

Loza, C. B. (2013). ¿La disminución de la mortalidad maternal es un simple problema técnico de adecuación cultural?.Historia, Ciências, Saúde-Manguinhos, 20(3), 1082-1085.

Loza, C. B. (Ed.). (2012). Las compañeras en el alumbrar. Despejando la penumbra en el arte obstetric. Bolivia 1237-2012. La Paz: UNFPA.

Luerssen, J. S. (2011). Illness and Household Reproduction in a Highly Monetised Rural Economy: A Case from the Southern Peruvian Highlands. Journal of Anthropological Research, 49(3), 255-281.

Manger, L. N. (1992). History of medicine. New York: Marcel Dekker, Inc.

Manzoni, M. (2015). Santa Cruz de la Sierra, una ciudad que busca su espacio. Ciudades. 9, 135-160.

Marland, H. \& Rafferty, A. M. (1997). Midwives, society, and childbirth: Debates and controversies in the modern period. London: Routledge.

Marquez, M. N. \& Pacheco, C. (1964). Midwifery lore in New Mexico. The American Journal of Nursing, 64(9), 81-84.

Martin, E. (2001). The Woman in the Body: A Cultural Analysis of Reproduction. Boston: Beacon Press. 
Mathez-Stiefel, S.-L., Vandebroek, I., \& Rist S. (2012). Can Andean medicine coexist with biomedical healthcare? A comparison of two rural communities in Peru and Bolivia. Journal of Ethnobiology \& Ethnomedicine, 8(26), 1-14.

Maupin, J. N. (2008). Remaking the Guatemalan midwife: Health care reform and midwifery training programs in highland Guatemala. Medical Anthropology, 27(4), 353-382.

Millenium Project. (2006). What they are. Retrieved from http://www.unmillenniumproject.org/goals/.

Ministerio de Salud y Deportes. (2006). Libro Marco Legal: Seguro Universal Materno Infantil. La Paz: Ministerio de Salud y Deportes.

Moloney, A. (2010). Difficulties hit Bolivia's programme for pregnant women. Lancet, 375(9730), 1955.

Morgan, L. (1997). Imagining the unborn in the Ecuadoran Andes. Feminist Studies, 23(2), 322-350.

Mulhall, A. (1996). Anthropology, nursing and midwifery: A natural alliance? International Journal of Nursing Studies, 33(6), 629-637.

Murphy-Lawless, J. (1996). Reading birth and death: A history of obstetric thinking. Cork: Cork University Press.

Oakley, A. (1984). The captured womb: A history of the medical care of pregnant women. Oxford: Basil Blackwell.

Oakley, A. (1994). Essays on women, medicine and health. Edinburgh: Edinburgh University Press.

Página Siete. 2015. Implante intradérmico femenino es el anticonceptivo más usado.

Retrieved from http://www.paginasiete.bo/sociedad/2015/1/28/implanteintradermico-femenino-anticonceptivo-usado-45469.html.

Paulson, S. \& Bailey, P. (2003). Culturally Constructed Relationships Shape Sexual and Reproductive Health in Bolivia. Culture, Health \& Sexuality, 5(6), 483-498.

Platt, T. (2002). El feto agresivo: Parto, formación de la persona y mitohistoria en los Andes. Estudios Atacameños, 22, 127-155.

PNUD. (2007). Objetivos de Desarollo del Milenio. Santa Cruz. Situación Actual, Evaluación y Perspectivas. La Paz. PNUD.

Rapp, R. (1999). Testing women, testing the fetus: The social impact of amniocentesis in America. New York: Routledge.

Rattner, D. (2008). Humanizing childbirth care: brief theoretical framework. Transl. by M. A. Gazzotti Vallim, Interface (Botucatu), 4, 1-12. 
Simonds, W., Katz Rothman, B. \& Meltzer Norman, B. (Eds.). (2007). Labouring on: Birth in transition in the United States, New York: Routledge.

Stone, P. K. (2009). A history of Western medicine, labour, and birth. In H. Selin \& P. K. Stone (Eds.), Childbirth across cultures: Ideas and practices of pregnancy, childbirth and the postpartum (pp. 41-53).Dodrecht: Springer.

Taylor, J. S., Layne, L. L. \& Wozniak, D. (Eds.). (2004). Consuming motherhood. New Brunswick: Rutgers University Press.

Tiefer, L. (1994). The Medicalisation of Impotence. Normalizing Phallocentrism. Gender \& Society, 8(3), 363-377.

Tremayne, S. (2001). Introduction. In S. Tremayne (Ed.). Managing reproductive life: Crosscultural themes in fertility and sexuality (pp. 1-24). New York: Berghahn Books.

UNFPA \& FCI/Bolivia. (2011). Mujeres Indígenas: Salud y Derechos. La Paz: UNFPA/AECID.

UNFPA. (2011). Evaluación Independiente del Programa de País Bolivia 2008-2011. New York: UNFPA.

UNFPA. (2016). Bono Juana Azurduy, Retrieved from http://bolivia.unfpa.org/content/bonojuana-azurduy.

Van Teijlingen, E. et al., (Eds.). (2004). Midwifery and the medicalisation of childbirth: Comparative perspectives. New York: Nova Science Publishers, Inc.

WHO \& UNICEF. (1990). Revised 1990 estimates of maternal mortality: A new approach by WHO and UNICEF. Retrieved from http: //whqlibdoc.who.int/hq/1996/WHO_FRH_MSM_96.11.pdf.

WHO. (1997). Managing maternal and child health programmes: a practical guide. Manila: WHO.

WHO. (2006). Mortality Country Fact Sheet 2006: Bolivia. Retrieved from http: //www.who.int/whosis/mort/profiles/mort_amro_bol_bolivia.pdf.

WHO. (2010). Monitoring Emergency Obstetric Care: A Handbook, vol.30. Geneva: WHO.

Young, A. (1982). The anthropologies of illness and sickness. Annual Review of Anthropology, 11, 257-285.

Zulawski, A. (2007). Unequal Cures: Public health and political change in Bolivia 19001950. Durham: Duke University Press. 